lution and the want of those states that were present in the breast (warmth and moisture), is feasible.

But to return from this digression to the case of another parasitic disease, supposed to furnish an exception, as regards the possession of the characteristic maik of tinea- $\mathrm{I}$ mean "sycosis." Authorities affirm that the microsporon mentagrophyta is confined to the follicle and the exterior of the hair. So far as my examinations go, this is a mistake. Very frequently, in the earliest stage of sycosis, before the fungus has reached the part of the hair which is in the follicle, the cut ends will be found infilitrated by its sporules. This happened in my own case. I inoculated myself by accident, and many of the hairs extracted were quite healthy, with the exception of the cut edises and immediately adjoining part. The assertion that in sycosis the fungus never extends beyond (out of) the follicle is erroneous.

In true idiopathic tinea decalvans, the sporules are to be found after careful search. You may require to examine several hairs before you succeed. Liquor potasse must always be used, and sufficient time allowed to elapse for the parts to become transparent. This, I know, is contrary to the experience of good observers. It is especially in this affection that absence of fungus has been noticed; but most observers confound secondary alopecia, or atrophy, with true tinea decalvans. The bald patch may be a sequela of any of the other tinex (due to destruction of the follicles), and of course there need not be any parasite present in such a case. Such a state is a secondary disease, and it is also an effect of true idiopathic tinea decalvans. Atrophy of the hairs is not a distinctive mark of tinea decalvans, for it occurs in every other variety of tinea. The distinguishing features of tinea decalvans are $a b$ sence of secretion and less severity of the affection of the hairs, in consequence of which they do not become brittle and break off, but remain till the follicle can retain them no longer. Their loss seems to be the commencement of the disease; whereas it is only the final effect. The disease is said by good authorities to be acute. Indeed it is not; it is the least acute of any of the tiner.

The practical point to remember in regard to the matter of tinea is, that whenever you meet with a case of skin disease in which you find the parasite sometimes present and sometimes absent, you are not to jump at the erroneous conclusion, like Mr. Hogg, that the parasite plays no part in the causation of the disease, and that it is accidental. Certainly, it is (practically) true that the fungus is not the cause of the eruptive disease, and is so far accidental; but it is the cause of the tinea present in those cases where the parasite is found, for if you will examine the hairs you will find the microscopic characteristic appearances in the one case, and not in the other. For instance, Mr. Hogg states that in twenty cases of lepra and psoriasis, he found the fungus in one half, in two of three of lichen, four of six of eczema, \&c.; and he argues that the parasite cannot be the cause of the disease (the eruption), and so far he is correct; but it is evident that he entirely misunderstands the true parasitic disease. No one has called attention to this error into which observers have fallen. The chronic skin diseases occur in situations where the hairs are few in number, and the effect of the parasitic growth is of no moment compared with the concomitant eruption.

(To be concluded.)

\section{SYPHILIS, WITH THE HYMEN UNBROKEN.}

By REDFERN DAVIES, EsQ., M.R.C.S., SURGEON TO THE BIRMINGPAYI WORLHOUSE INITIMARX,

THE two following cases, which were recently in the venereal wards of the infirmary, may be deemed interesting in a medicolegal point of view, illustrating in a most striking manner that the existence of a hymen is consonant even with venereal disease in a prostitute. I may remark that these cases have been examined by Dr. Bell Fletcher and others.

Case 1.-Elizabeth $\mathrm{C}-$ - aged seventeen. Menstruation, which commenced at the age of twelve, has continued irregularly ever since. She has all the marks of puberty well developed, and a lively disposition. Has been living in a brothel as the servant of the house for the last eight weeks. After she had been there $a$ fortnight, she slept with a man aged trrenty. five, who, although aided by her, was unable to attain his objest. During the following fortnight, according to her own statement, about a dozen other men shared a similar fate to the first, all of them expressing themselves dissatisfied. Each attempt caused her pain; but it was only with the fourth man, who used great force, that she bled, and then only a little. Five weeks back, she perceived a thick yellow discharge from the vagina, accompanied with heat and scalding upon micturition; and in another week she found a small sore upon the labia. These symptoms became worse, and prevented her from attempting intercourse, so that four weeks have elapsed since the last occasion.

Upon admission, Feb. 27th, she was found to labour under a vaginal discharge, with pain on passing urine, and tumid lips of vagina. On the right labia was a non-indurated chancre. Passing the finger into the vagina, it was arrested just within the lips; and, as it cansed much pain, the attempt was not persevered in. Several days after, when, by treatment and rest, all swelling had subsided, another examination was very carefully made, when it was found that the hymen existed, and in a most perfect state and position. The little finger could be carried through into the vagina, which was found to be of a natural calibre and condition; but this 'was attended with pain, and she averred most positively that it was the first time that an introduction had been made so deep into the passage.

CASE 2. - Sarah H constitution; has never menstruated, and the signs of puberty are but small. Some six months before admission she was persuaded by a man, aged about forty, to permit him to have intercourse with her. The attempt caused her pain, and a few drops of blood were seen upon her dress; he was, however totally unable to penetrate beyond the external lips. A second attempt was made about four months afterwards, and a third a month since, with similar results; the men being about twenty-five years of age. She has had a vaginal discharge, with heat and pain on micturition, for the last three weeks.

Upon admission, Feb. 26th, the usual signs of gonorrhoea were present; but upon examination, the hymen was found perfect and in its natural site. The little finger passed with difficulty through it into the vagina, which was in all respects normal.

Birmingham, June, 1859.

\section{a Alintor}

OF THE PRACTICE OF

\section{MEDICINE AND SURGERY IN THE}

\section{HOSPITALS OF LONDON.} Nulla est alia pro certo noscendi via, nisi quam plurimas et morborum et
dissectionum historias, tam aliorum proprias, collectas habere et inter se comparare.-MTorgagNu. De Sed. et Caus. Mrorb., lib. 14. Procemium.

\section{ST. BARTHOLOMEW'S HOSPITAL.}

NECROSIS OF THE LOWER JAW FROM THE FUMES OF PHOSPHORUS; COMPLETE REMOVAL OF THE BONE, FOLLOWED BY RECOVERY.

(Under the care of Mr. Holmes Coote.)

ForTUNately for us, in this country we do not see so many of the terrible effects arising from the employment of phosphorus in lucifer-match making as are witnessed in France and Germany, where such manufactures are most extensively carried on. Necrosis of the lower jaw is, perhaps, the only special result which comes under the notice of the English surgeon, and which does not appear until the teeth first become affected. Diseases of the lungs, in consequence of the manufacture, are with us almost unknown; whilst in Paris and elsewhere many of the workwomen have had to leave their employment from what were looked upon as neglected colds, terminating in consumption, but which were, in reality, the result of the inhalation of an atmosphere, which Dr. Dupasquier found to consist principally of hypophosphoric acid, probably mixed with small quantities of phosphuretted hydrogen, and possibly the phos- 
phorus itself in the form of vapour. The breath of these people at night becomes luminous. The valuable Report of Dr. Waller Lewis, presented to both Houses of Parliament in 1855 , "On the Regulation of Noxious Trades and Occupations in France," very clearly shows that bronchitis, often in a very severe form, is a common affection amongst many of the workpeople, and, in proof of this, he furnishes abundant evidence from various sources, as well as from personal observation.

Now, although in this country we are free from the worst phases of the disease, it still behoves manufacturers to consider whether, in place of phosphorus, some other chemical substance could not be introduced which would produce the igniting effects desired, without the sickening and unpleasant alliaceous odour which invariably arises from this element. Such matches are now being manufactured in Paris by M. Canouil. Amongst other varieties, they are made of chlorate of potass, powdered flint or glass, bichromate of potass, gum or dextrin, and water, made into a paste. A simple friction produces combustion; there is no unpleasant smell, because there is no phosphorus, and, what is of considerable importance, their manufacture is not injurious to the workpeople. Much misery and suffering are therefore obviated amongst those who are employed in the factories.

In a former "Mirror," when placing upon record an instance of necrosis of the lower jaw, arising from the fumes of phosphorus, in which Mr. Thomas Wakley removed the bone with success at the Royal Free Hospital, we devoted some attention to the consideration of this subject, and we urged the propriety of the periodical examination of the teeth of those employed in factories where it was used, so that the spread of its destructive inflinences might be arrested. We referred to several other cases which had appeared in our "Mirror;" but Mr. Wakley's was one of the most remarkable we had seen. The patient has since given $u p$ his old employment. (TH LAfrcet, vol. ii. 1857 , p. 31 , and vol. i. 1855 , p. 585.)

Besides necrosis of the jaw and diseases of the lungs, which arise from phosphoric vapours, it has been ascertained by $M$. Moignot that the women employed in the manufacture of lucifer-matches are very liable to miscarry, and so fully aware have the work women become of this peculiarity that advantage has been taken of it to procure abortion.

In the case which we record to-day, the disease did not appear until the gums in contact with the diseased teeth became ulcerated, which produced pain and swelling of the jaw, with ultimate complete death of the entire bone. It is somewhat remarkable, that one condyle, together with the coronoid processes of the rami, should have been withdrawn entire, particularly when we consider the important muscles which are attached to the latter. The phosphoric infiltration remains in the soft structures of the cheeks, thus giving the patient an artificial appearance of health.

Charles T___ aged thirty-nine, a wax-taper dipper, was admitted into the above hospital on the $28 \mathrm{th}$ of December 1858. About thirteen months ago, he complained of much pain and swelling about his lower jaw, commencing in one of the right incisor teeth. Abscesses formed and burst externally through the skin of the cheek. When admitted, his face generally was much swollen, exhibiting the peculiar pasty appear ance witnessed in necrosis of the jaw arising from the fumes of phosphorus. Several fistulæ were noticed at the lower margins of the jaw, communicating with lead bone, and giving passage to matter. On opening the mouth, the lower jaw was seen exposed, denuded of periosteum, and quite black in colour ; it was also slightly movable. He had been working for seven. teen years at his calling before the ulceration of his gums commenced.

On the 9th of April, chloroform was given by Dr. Martin, and, when anæesthesia was complete, Mr. Coote proceeded to saw through the symphysis of the lower jaw within the mouth; after which, by the aid of a pair of forceps, the left half of the lower jaw was drawn out entire, without its condyle, but with the ascending ramus. The same proceeding was adopted with the right half of the jaw, which came away with equal facility, but with the condyle, which appeared to be healthy. Some hæmorrhage necessarily ensued, but it was not great, and spontaneously ceased. For some three or four days after the operation, the patient complained of pain in the face, but it gradually diminished, and soon ceased entirely. His health now began to improve, under the use of a liberal diet; his appetite increased, and his strength returned. The investing periosteum of the old bone now began to throw out fresh osseous material, and a new lower jaw was in the process of formation, as has been noticed in other and similar instances. The pasty appearance of the face, and the puffiness of the cheeks, how. ever, remain, and these would seem to be almost the perma. nent consequences of the affection. He left the hospita short time back, completely restored in health, and able to speak and articulate with tolerable distinctness.

On examining the bone when cleaned and dried, we found it to be massive, and of nearly double the weight of the healthy bone. It was covered in some places with unhealthy lymph, undergoing osseous transformation.

Ten years ago, there was a patient in this hospital, under Mr. Stauley's care, who was a fellow-workman in the same factory, and whose lower jaw was affected with necrosis arising from the same cause.

\section{CLINICAL RECORDS.}

\section{RELAPSE IN TYPHOID FEVER, FROM INCREASED DIET.}

Dr. Graves has observed, in his lectures on "Clinical Medicine," that in the treatment of long fevers, it is important for the physician not to let his patients die of starvation. This is a maxim of too much value to be overlooked; yet, again, he states that great discrimination is required in the choice of food, for although the patient should not be allowed to starve, it is essential not to run into the opposite extreme; for if so. the stomach will be overloaded, and serious consequences produced, such as a relapse of the fever, gastro-enteric irritation or actual inflammation. It is by no means unusual in the treatment of fever, when convalescence has become established, to allow of moderately increased diet with advantage, but sometimes this liberty is abused by the patient himself. A striking instance of this came under our notice at Guy's Hospital on the 2Ist of June. A man, twenty-four years of age, who was admitted, under Dr. Wilks's care, on the 23rd of May, with typhoid fever, accompanied by the characteristic rose-coloured rash, became convalescent; and although his diet was increased, he carried bis feeding beyond what it should have been, and the consequence was a relapse of the fever, with a recurrence of the rash. He is again convalescent, but weak, and is allowed suitable and regulated diet. We have heard some practitioners declare they have gratified their patients with whatever they desired, and in any quantity they pleased. But such practice is to be condemned, and the rational physician will hardly fall into so grave an error. Dr. Graves refers to the case of a young lady who ate some beef-steak, contrary to his orders, at an early period of convalescence from fever. She relapsed almost immediately, and died of enteritis in thirty-six hours.

\section{EXTRACTION OF A THERMOMETER-TUBE FROM} THE URINARY BLADDER.

As immense variety of foreign bodies have been found in the bladder, both of males and females. Hair, beans, fruitstones, ears of corn, portions of bougie, nails, bullets, small bones, pins, needles, string, stalks of flowers, \&c. \&c, are amongst the substances enumerated by Mr. Coulson, in his work on the Bladder (chap. xix.), as having been extracted from this viscus. If allowed to remain, they easily form the nucleus of a stone. On the 22nd of June we witnessed the extraction of a thermometer-tube from the bladder, at St. Mary's Hospital. The patient was a young man, aged twenty two, admitted under Mr. Coulson's care on the 20th June. He had for many years been subject to nocturnal emissions, and, after a long course of doctoring, he resorted to the expedient of introducing a glass thermometer-tube along the urethra and into the bladder, as a species of impromptu bougie. He accomplished the introduction successfully, although not without difficulty; but on attempting its withdrawal the glass tube broke, and a part remained in the bladder. Its presence did not cause any considerable inflammation; he suffered little pain, and micturated without difficulty. There was no urgency to pass urine; but after the bladder was emptied he experienced pain in the peritoneum, but not of an acute character. There was a slight admixture of blood with the urine. He was a nerrous and somewhat weakly subject, and under the influence of spermatophobia. Mr. Coulson operated as in lithotomy, and removed the piece of tube entire, so as accurately to fit the other portion. The piece extracted measured between three and four inches in length. Some little difficulty was experienced in withdrawing it, owing to its being placed across the neck of the bladder. But little blood was lost. The 